\title{
Therapeutic potential of deep brain stimulation of the nucleus accumbens in morbid obesity
}

\author{
${ }^{*}$ D. L. Marinus Oterdoom, MD, ${ }^{1}$ Gertjan van Dijk, PhD, ${ }^{2}$ Martijn H. P. Verhagen, MD, ${ }^{1,3}$ \\ V. Carel R. Jiawan, MD, ${ }^{4}$ Gea Drost, MD, PhD, ${ }^{5}$ Marloes Emous, MD, ${ }^{6}$ André P. van Beek, MD, PhD, \\ and J. Marc C. van Dijk, MD, PhD'
}

Departments of ${ }^{1}$ Neurosurgery, ${ }^{4}$ Psychiatry, ${ }^{5}$ Neurology, and ${ }^{7}$ Endocrinology, University of Groningen, University Medical Center Groningen; ' 2 Department of Behavioral Neurosciences, University of Groningen, Groningen Institute for Evolutionary Life Sciences (GELIFES), Cluster Neurobiology, Groningen; ${ }^{3}$ Department of Neurosurgery, Noordwest Ziekenhuisgroep, Alkmaar; and ${ }^{6}$ Department of Bariatric and Metabolic Surgery, Medical Center Leeuwarden, The Netherlands

OBJECTIVE Morbid obesity is a growing problem worldwide. The current treatment options have limitations regarding effectiveness and complication rates. New treatment modalities are therefore warranted. One of the options is deep brain stimulation (DBS) of the nucleus accumbens (NAC). This review aims to summarize the current knowledge on NAC-DBS for the treatment of morbid obesity.

METHODS Studies were obtained from multiple electronic bibliographic databases, supplemented with searches of reference lists. All animal and human studies reporting on the effects of NAC-DBS on body weight in morbidly obese patients were included. Articles found during the search were screened by 2 reviewers, and when deemed applicable, the relevant data were extracted.

RESULTS Five relevant animal experimental papers were identified, pointing toward a beneficial effect of high-frequency stimulation of the lateral shell of the NAC. Three human case reports show a beneficial effect of NAC-DBS on body weight in morbidly obese patients.

CONCLUSIONS The available literature supports NAC-DBS to treat morbid obesity. The number of well-conducted animal studies, however, is very limited. Also, the optimal anatomical position of the DBS electrode within the NAC, as well as the optimal stimulation parameters, has not yet been established. These matters need to be addressed before this strategy can be considered for human clinical trials.

https://thejns.org/doi/abs/10.3171/2018.4.FOCUS18148

KEYWORDS obesity; food addiction; deep brain stimulation; nucleus accumbens; reward

$\mathrm{C}$ LASS II obesity (BMI $35-40 \mathrm{~kg} / \mathrm{m}^{2}$ ) and class III obesity $\left(\mathrm{BMI}>40 \mathrm{~kg} / \mathrm{m}^{2}\right)$ are serious medical conditions with an increasing global prevalence. Current estimates in the adult population in western countries vary from $3 \%$ to $8.5 \%$ for class II, and $1 \%-3.1 \%$ for class III obesity, depending on geographical region. ${ }^{32,61}$ These numbers continue to increase. ${ }^{20}$ There is an increased mortality rate when BMI rises above $30,{ }^{10,39}$ with a decreased life expectancy of 10 years in class III obesity. . $^{59,70}$ Furthermore, obesity has a significant negative impact on quality of life. ${ }^{60}$ Weight loss improves quality of life and reverses comorbidities, such as dyslipidemia and diabetes mellitus. ${ }^{68}$

Success rates for various interventions that aim to re-

ABBREVIATIONS AMED = Allied and Complementary Medicine; $B S=$ bariatric surgery; $\mathrm{CINAHL}=$ Cumulative Index to Nursing and Allied Health Literature; $\mathrm{DBS}=$ deep brain stimulation; GABA = $\gamma$-aminobutyric acid; ICTRP = International Clinical Trials Registration Platform; NAC = nucleus accumbens; OCD = obsessive-compulsive disorder; WOS $=$ Web of Science.

SUBMITTED March 26, 2018. ACCEPTED April 24, 2018.

INCLUDE WHEN CITING DOI: 10.3171/2018.4.FOCUS18148.

${ }^{*}$ D.L.M.O. and G.v.D. contributed equally to this work. 
TABLE 1. Electronic databases and other resources

\begin{tabular}{lc}
\hline \multicolumn{1}{c}{ Resource } & $\begin{array}{c}\text { Date of Search/ } \\
\text { Last Issue } \\
\text { Searched }\end{array}$ \\
\hline Electronic databases & Until 1/1/2018 \\
\hline Cochrane Library & Issue 1/2018 \\
\hline EMBASE & \\
\hline MEDLINE & \\
\hline psychINFO & Until 1/1/2018 \\
\hline CINAHL & \\
\hline Gray literature & \\
\hline AMED & \\
\hline Web of Science Proceedings & \\
\hline Ongoing trials & \\
\hline Australian New Zealand Clinical Trials Registry & \\
\hline ClinicalTrials.gov & \\
\hline EU Clinical Trials Register (EU-CTR) & \\
\hline ISRCTN & \\
\hline Brazilian Clinical Trials Registry (ReBec) & \\
\hline Chinese Clinical Trial Registry, 31 March 2014 \\
\hline Clinical Trials Registry-India, 31 March 2014 \\
\hline Clinical Research Information Service-Republic \\
of Korea
\end{tabular}

duce BMI have a large interindividual variability. This variability underlines the fact that causes for obesity are multifactorial. Compared to behavioral and pharmacological interventions, bariatric surgery (BS) is currently the most effective treatment in severe obesity. ${ }^{9} \mathrm{BS}$ results in weight loss ranging from $20 \%$ to $60 \%$ of total body weight with a concomitant improvement in morbidity. ${ }^{41,46,52}$ However, $20 \%-40 \%$ of patients undergoing BS fail to lose sufficient weight or regain weight after initial weight loss, 1,19,42 which may be attributed to personality traits and pathological eating behavior. ${ }^{2,5,40,43,62}$

More knowledge about neurobehavioral mechanisms causing morbid obesity is needed to develop tailored therapies adjustable for individual patients. Development of new treatment strategies for obesity cannot remain "brainless." ${ }^{56}$ In the brain, the nucleus accumbens (NAC) is an anatomical structure located in the ventral striatum that plays a major role in the reward system. The NAC regulates motivation and action. ${ }^{54}$ Hyperactivity of the NAC has been established to play a role in obesity, ingestion, and reward-related learning: showing pictures of high-caloric food induces activation of the NAC in humans. ${ }^{34}$ This activation is more prominent in obese subjects compared to nonobese subjects in a fasted state. ${ }^{58}$ After testing, patients with activated NAC are more likely to eat. ${ }^{38,47}$ In a fed state, the NAC remains more active in obese persons. ${ }^{8}$

In certain cases, obesity may develop as a form of addiction much like other addiction disorders, such as alcohol, drugs, and gambling. The incentive sensitization theory, which was developed in the context of drug addiction, states that food cues can play a role in visual attraction and strengthen the desire to eat. ${ }^{11,22,72}$ This effect is stronger in overweight persons. The NAC plays a major role in incentive sensitization in drug addiction. ${ }^{14,58,59}$

The NAC has already proven to be a successful target of deep brain stimulation (DBS) for other neuropsychiatric diseases ${ }^{18,65}$ and this review aims to summarize the available evidence regarding a potential role for DBS of the NAC in the treatment of obesity.

\section{Methods}

Sources of potentially relevant records were identified (Table 1). A query to extract relevant records from these resources was formulated (Table 2). Retrieved records were screened by title, abstract, and full text when deemed potentially applicable and relevant data were extracted. Any report on the effect of DBS of the NAC in human or animal subjects on body weight change or caloric intake was included, if an English abstract was available. References of relevant original articles and reviews were checked for additional relevant papers.

\section{Results}

Searching the different databases according to the aforementioned strategy yielded 28 records in Medline, 54 records in Embase, 68 records in Web of Science (WOS), 5 records in the Cochrane Library, 16 records in the International Clinical Trials Registration Platform (ICTRP), and 3 records in a combined search of the Allied and Complementary Medicine (AMED), Cumulative Index to Nursing and Allied Health Literature (CINAHL), and psycINFO databases (i.e., the EBSCO database). After screening these articles for title, abstract, full text, and filtering duplicates, 5 relevant papers discussing animal experimental data, 3 case reports, and 3 relevant reviews were identified. Two human trials in progress were identified investigating DBS for obesity. The references of the original articles and relevant reviews were checked for relevant papers, which yielded no additional studies (Fig. 1).

\section{Animal Experimental Data}

The animal experimental data are summarized in Table 3. In rodents, the NAC is divided into three functionally distinct subregions, i.e., the core, the lateral shell, and the medial shell, ${ }^{48}$ but in humans these anatomical subdivisions are controversial..$^{50}$

Halpern et al. ${ }^{27}$ investigated the effects of DBS of the left NAC shell on obesity in mice. Eight mice were put on a high-fat diet for 16-20 weeks and then grouped into 4 weight-matched pairs. After stabilization of body weight and caloric intake, half of the mice were put on a 4-day trial of continuous high-frequency stimulation $(150 \mu \mathrm{A}$, 
TABLE 2. Applied search strategy

\begin{tabular}{|c|c|}
\hline Database & Search Strategy \\
\hline Medline & $\begin{array}{l}\text { (Striat*[title/abstract] OR accumbens[title/abstract] OR NAcc[title/abstract] OR Acb[title/abstract] OR NA[title/abstract]) AND } \\
\text { (DBS[title/abstract] OR "deep brain stimulation"[title/abstract]) AND (Obesit*[title/abstract] OR *weight[title/abstract] OR } \\
\text { weight*[title/abstract] OR intake[title/abstract] OR eat*[title/abstract]) }\end{array}$ \\
\hline Embase & $\begin{array}{l}\text { striat*:ab,ti OR accumbens:ab,ti OR nacc:ab,ti OR nac:ab,ti OR acb:ab,ti OR na:ab,ti AND (dbs:ab,ti OR ‘deep brain } \\
\text { stimulation':ab,ti) AND (obesit*:ab,ti OR overweight:ab,ti OR weightti,ab OR intake:ab,ti OR eat*:ab,ti) AND [embase]/lim }\end{array}$ \\
\hline WOS & $\begin{array}{l}\text { \# 1: TOPIC: (striat*) OR TOPIC: (accumbens) OR TOPIC: (NAcc) OR TOPIC: (NAC) OR TOPIC: (Acb) OR TOPIC: (NA) } \\
\text { \# 2: TOPIC: (DBS) OR TOPIC: (“deep brain stimulation”) } \\
\text { \# 3: TOPIC: (obesit*) OR TOPIC: (“weight*) OR TOPIC: (intake) OR TOPIC: (eat*); \# 4: \#1 AND \#2 AND \# } 3\end{array}$ \\
\hline $\begin{array}{l}\text { AMED, CINAHL, } \\
\text { psycINFO }\end{array}$ & $\begin{array}{l}\text { (AB striat* OR accumbens OR NAcc OR NAC OR Acb OR NA) AND (AB DBS OR 'deep brain stimulation') AND (AB obesit* } \\
\text { OR overweight OR weight* OR intake OR eat*) }\end{array}$ \\
\hline Cochrane Library & DBS OR “Deep brain stimulation" \\
\hline ICTRP & Deep brain stimulation AND accumbens; Deep brain stimulation AND obesity \\
\hline
\end{tabular}

Queries are specified for each search engine.

$60 \mu \mathrm{s}, 160 \mathrm{~Hz}$ ) and compared to their matched controls regarding weight and intake. A crossover trial was performed afterwards. Video monitoring revealed no signs of motor side effects that could affect the ability to eat. A significant decrease from baseline body weight was detected after DBS.

These authors also investigated the effects of DBS of the left NAC on binge eating in 10 mice. ${ }^{27}$ The electrode was placed in the NAC shell of 8 mice, and in the NAC core of 2 mice. The mice were put on a limited access protocol to high-fat food, known to induce binge eating. After stabilization of binge size, a protocol was started with high-frequency stimulation on alternating days (150 $\mu \mathrm{A}, 60 \mu \mathrm{s}, 160 \mathrm{~Hz}$ ). Video monitoring revealed no signs of motor side effects that could affect the ability to eat. The number of calories consumed during the binge was significantly lower on days with stimulation in the mice with NAC shell stimulation, compared to days without. No significant effects were found in the 2 mice with NAC core stimulation.

van der Plasse et al. ${ }^{63}$ tested the effect of DBS of the lateral NAC shell, medial NAC shell, and NAC core on sucrose preference, food intake, and motivation to respond for sucrose under a progressive ratio schedule for reinforcement in rats. The groups consisted of 23 medial NAC shell, 20 lateral NAC shell, and 21 NAC core rats. Outcomes were compared intraindividually to the baseline situation (implantation, connection to the wiring system without stimulation) and within groups. Stimulation intensity was varied, while frequency and pulse duration were kept stable at $130 \mathrm{~Hz}$ and $60 \mu \mathrm{s}$. Stimulation at 100 $\mu \mathrm{A}$ in the medial NAC shell increased intake of normal chow. Stimulation at $100 \mu \mathrm{A}$ in the lateral NAC shell reduced the number of sucrose rewards obtained during the progressive ratios. For the lower intensities, no effects were observed. There was no influence of stimulation on sucrose preference. No effects were observed during core stimulation.

Zhang et al. ${ }^{73}$ evaluated the effect of DBS of the NAC shell on intake and weight gain in rats on a high-fat diet. Sixteen rats were put on a high-fat diet leading to diet-induced obesity and 16 received normal chow. All rats were implanted with left-sided medial shell electrodes, but only half of the animals in each group received stimulation.

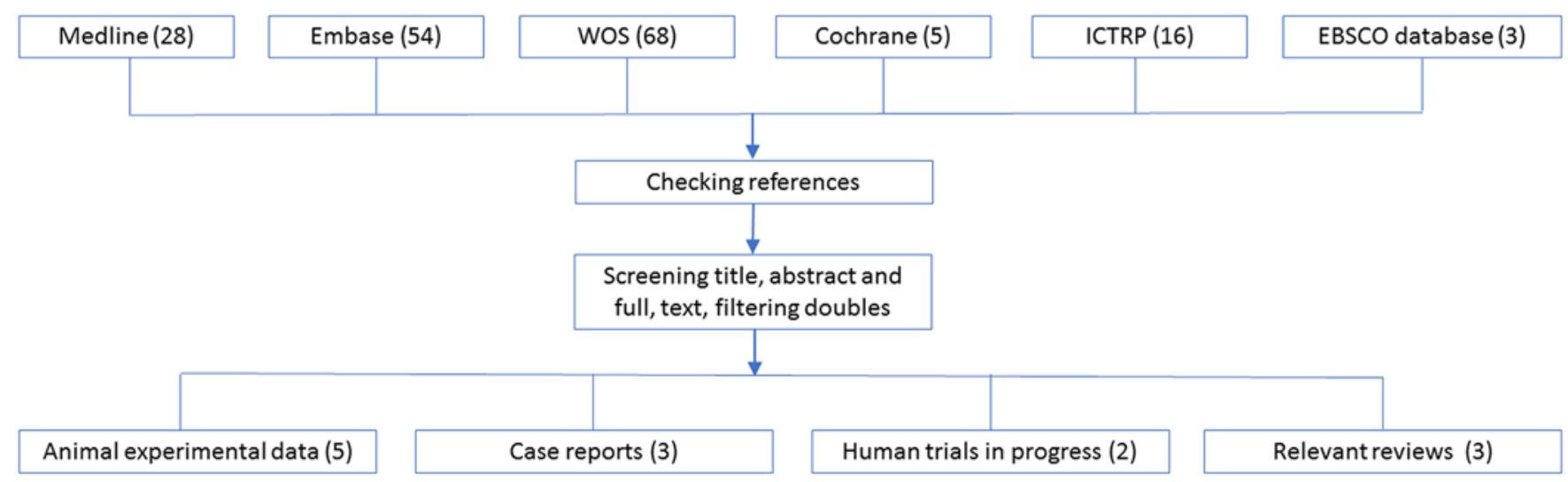

FIG. 1. Flowchart. Illustration of the number of retrieved records in each source and the number and types of relevant papers identified after screening the retrieved records for title, abstract, and full text, and filtering duplicates. The references of relevant papers were checked for additional relevant papers. EBSCO databases = AMED, CINAHL, and psycINFO. 
TABLE 3. Summary of animal experimental data

\begin{tabular}{llll}
\hline \multicolumn{1}{c}{ Authors \& Year } & Electrode Position in NAC & No. of Animals & \\
\hline Halpern et al., 2013 & & & \\
\hline Obesity & Lt shell & $8^{*}$ & Significant decrease in body weight \\
\hline Binge eating & Lt shell & $8^{*}$ & Reduction in binge size \\
\hline Van der Plasse et al., 2012 & Lt core & $2^{*}$ & No change \\
\hline Normal diet & Bilat lateral shell & $23 \dagger$ & Reduced motivation to seek food rewards \\
\hline & Bilat medial shell & $20 \dagger$ & Increased intake of normal chow \\
\hline Zhang et al., 2015 & Bilat core & $21 \dagger$ & No change \\
\hline Obesity & & & \\
\hline Doucette et al., 2015 & Lt medial shell & $16 \dagger$ & Decline in caloric intake \& weight gain \\
\hline Binge eating & & & \\
\hline Wei et al., 2015 & Bilat core & $18 \dagger$ & Reduction in binge size, no change in binge size when binge \\
\hline Food deprivation before stimulation & Shell rt & & sessions were resumed after a 1-mo pause \\
\cline { 2 - 4 } & Core rt & $10 \dagger$ & Decreased high-fat food intake \\
\hline
\end{tabular}

All subjects were rodents. In all experiments high-frequency stimulation was applied.

* Mice.

† Rats.

Stimulation settings were $500 \mu \mathrm{A}, 130 \mathrm{~Hz}$, and $90 \mu \mathrm{s}$. The stimulated normal chow rats did not alter their caloric intake or their weight gain compared to their sham controls, but the animals with diet-induced obesity showed a clear decline in caloric intake and weight gain as compared to their controls.

Doucette et al. ${ }^{21}$ investigated the effect of bilateral high-frequency stimulation of the NAC core on binge size in a rat model for both "chronic" and "relapse to chronic" binge eating. Rats were placed on a diet to induce binge eating. Rats received either active or sham stimulation. After testing in the "chronic" binge eating state they did not engage in binge sessions for a month. Binge sessions were resumed (relapse to chronic) and active and sham stimulation states were applied again. Binge size was significantly reduced in the chronic binge eating state, but not in the "relapse to chronic" state following stimulation.

Wei et al. ${ }^{67}$ implanted right-sided unilateral electrodes in either the NAC shell $(n=10)$ or NAC core $(n=10)$ of rats. High-frequency stimulation in the shell, but not the core, induced decreased high-fat food intake during and after stimulation. In this experiment, a recording electrode was concomitantly placed in the lateral hypothalamic area. Nearly all lateral hypothalamic neurons were inhibited during high-frequency stimulation of the NAC shell, whereas the firing rate of the lateral hypothalamic neurons was hardly influenced during high-frequency stimulation of the NAC core. In a microdialysis study, this group showed that high-frequency stimulation of the NAC shell, but not the NAC core, induced increased $\gamma$-aminobutyric acid (GABA) levels in the lateral hypothalamic area during and after stimulation.

Even though the number of preclinical studies is limited, and study objectives and methods vary, common denominators can be identified. High-frequency stimulation of the NAC shell has a consistent effect of reduction of food intake and weight (gain) on animals with the various baseline conditions: obesity, ${ }^{27,73}$ binge eating, ${ }^{8}$ normal diet, ${ }^{63}$ and food deprivation. ${ }^{68}$ There is one exception in which high-frequency stimulation of the lateral NAC shell led to an increase of normal chow in rats on a regular diet. ${ }^{63}$ There is no effect of NAC core stimulation in all baseline conditions ${ }^{18,21,27,68}$ except for a reduction on binge size in one experiment. ${ }^{21}$ However, this effect diminished after a 1-month period in which binge sessions were interrupted. ${ }^{21}$ Taken together, these studies indicate that the effect of high-frequency stimulation of the NAC shell, especially the medial shell, is the most effective part of the NAC to treat obesity in animal experiments. There is no difference in the effect of uni- or bilateral high-frequency stimulation.

\section{Case Reports}

The case reports are summarized in Table 4. Mantione et al. ${ }^{45}$ reported a case of a 47 -year-old woman with nicotine dependence and obesity, who was treated with bilateral NAC DBS for therapy refractory obsessive-compulsive disorder (OCD). With a weight of $107 \mathrm{~kg}$ and a length of $1.70 \mathrm{~m}$, her BMI was $37 \mathrm{~kg} / \mathrm{m}^{2}$. Stimulus parameters were $3.5 \mathrm{~V}, 90 \mu \mathrm{s}$, and $185 \mathrm{~Hz}$. In the first 10 months after implantation she gained weight and reached a BMI of $39 \mathrm{~kg} /$ $\mathrm{m}^{2}$. After this period when most of her OCD symptoms had significantly improved, she chose to quit smoking and lose weight. She succeeded at both, losing $44 \mathrm{~kg}$ resulting in a BMI of $25 \mathrm{~kg} / \mathrm{m}^{2}$. She maintained this weight at the 2-year follow-up.

Harat et al. ${ }^{67}$ reported a 19 -year-old woman steadily gaining weight after having undergone craniopharyngioma surgery. When she weighed $151.4 \mathrm{~kg}$, she underwent 
TABLE 4. Summary of case reports

\begin{tabular}{|c|c|c|c|c|}
\hline Authors \& Year & Age (yrs), Sex & Primary DBS Indication & Intervention & Weight Loss \\
\hline Mantione et al., 2010 & $47, \mathrm{~F}$ & OCD & Bilat NAC & $44 \mathrm{~kg}, \mathrm{BMI}$ reduced from $39 \mathrm{~kg} / \mathrm{m}^{2}$ to $25 \mathrm{~kg} / \mathrm{m}^{2}$ \\
\hline Harat et al., 2013 & $19, \mathrm{~F}$ & $\begin{array}{l}\text { Obesity after craniopharyngioma } \\
\text { surgery }\end{array}$ & Bilat NAC & $19.6 \mathrm{~kg}, \mathrm{BMl}$ reduced from $53 \mathrm{~kg} / \mathrm{m}^{2}$ to $46 \mathrm{~kg} / \mathrm{m}^{2}$ \\
\hline Tronnier et al., 2018 & $40, \mathrm{~F}$ & Depression & Bilat NAC & $\begin{array}{l}30 \mathrm{~kg} \text {, weight loss (1.75 kg/month) after gastric bypass surgery, } \\
\text { which accelerated after DBS ( } 2.85 \mathrm{~kg} / \mathrm{mo})\end{array}$ \\
\hline
\end{tabular}

implantation with a bilateral NAC DBS system. After 3 months of stimulation, she had lost $19.6 \mathrm{~kg}$, reaching a BMI of $46.2 \mathrm{~kg} / \mathrm{m}^{2} .^{30}$

Tronnier et al..$^{62}$ present a case of a 40 -year-old woman who was treated with NAC-DBS to treat severe depression as a primary goal and obesity (BMI $66 \mathrm{~kg} / \mathrm{m}^{2}$ ) as a secondary goal. She underwent gastric bypass surgery 6 months before DBS. She lost $1.75 \mathrm{~kg} / \mathrm{month}$ afterwards. This rate accelerated to $2.85 \mathrm{~kg} / \mathrm{month}$ after DBS.

\section{Human Trials in Progress}

Two human trials in progress were identified. One is titled "Deep Brain Stimulation For Morbid, Treatment-Refractory, Obesity" (clinicaltrials.gov identifier: NCT01512134). This trial is a safety and efficacy study. It included 5 patients at least 24 months after gastric bypass surgery without evidence of a sustained improvement in BMI for at least 6 months. The intervention tested is DBS, but the target area is not specified. The primary outcome is percentage of excess weight loss. The study is completed, but no results are published to date. The second study is titled "PINS Stimulator System for Deep Brain Stimulation to Treat Obesity" (clinicaltrials.gov identifier: NCT02254395). This Phase 1 study aims to enroll 8 morbidly obese $\left(\mathrm{BMI}>40 \mathrm{~kg} / \mathrm{m}^{2}\right)$ patients for DBS. However, the target is not specified and the study is not yet recruiting.

\section{Reviews}

Three reviews were conducted, two by Halpern et al. ${ }^{28,29}$ and one by Betry et al. ${ }^{7}$ These reviews yielded no additional relevant original research papers. Their overall conclusion was that the NAC is a potential target for DBS in the treatment of therapy-refractory obesity. These reviews were all published more than 5 years ago.

\section{Discussion}

The rationale for NAC stimulation to target eating disorders is based on the established role of the NAC in ingestive behavior and on the accumulating evidence that obesity, at least in part, can be considered the result of addictive behavior toward food. $3,4,6,23,24,28$ The latter is relevant because positive results of NAC-DBS for compulsions and addiction are increasingly available. ${ }^{18,25,37,44,}$ $64,65,71$

\section{The NAC and the Reward Circuitry}

The NAC is part of the so-called reward circuitry. The term "reward" as used in scientific literature may desig- nate: 1) pleasure or hedonia, 2) appetitive motivation, and 3) reinforcement. These are discrete entities that do not need to coincide. Focusing on motivated behavior, different aspects can be dissociated through neurochemical or other manipulations, such as "wanting" vs "liking," or "preparatory/appetitive" vs "consummatory." 55

Anatomically, reward is mediated by a corticobasal ganglia network in which the basal ganglia fulfill the role of a "motivation-to-movement" interface. The NAC receives its inputs primarily from the olfactory and visceral-associated insula, from the ventromedial prefrontal cortex, and most likely from the medial prefrontal cortex on the one hand, and from the amygdala and the hippocampus on the other. These projections synapse on single fast-spiking GABAergic interneurons, which are believed to integrate the different cortical inputs before the information is transferred to the medium spiny projection cells. Output is delivered mainly to the pallidum and the midbrain (ventral tegmental area and medial substantia nigra) and to a lesser extent to the lateral hypothalamus and the extended amygdala. ${ }^{26}$

\section{The NAC and Its Relation to Ingestive Behavior and Obesity}

There is an association between activity and manipulation of activity in several subregions of the NAC and ingestive behavior in rodents.

Upon presentation of a conditioned stimulus (a retractable lever) associated with sucrose delivery, a subpopulation of neurons in the NAC exhibits increased firing, while other subpopulations of neurons show suppressed activity compared to baseline. This activity is associated with approach behavior to the stimulus and is not present upon presentation of a comparable cue (another lever) unrelated to sucrose delivery. These cue-related neural responses may represent neural responses in the human reward circuitry and model the compulsive nature of addiction in humans. ${ }^{15}$

In the anterior NAC, multiple sites have been identified that show a decreased activity just before and during feeding. Stimulation at these sites at 15 or $40 \mathrm{~Hz}$ disrupts licking of water with or without sucrose. ${ }^{36}$ Neuroimaging studies show a relationship between activation of the NAC and obesity. Several studies show an increased activation of the NAC in obese individuals in response to food stimuli. ${ }^{17,49,58}$ A comparison of 12 age- and sex-matched individuals with and without obesity showed an increased activation of the NAC in the obese individuals in response to both pleasant and unpleasant taste sensations. ${ }^{57}$ Obese women exhibit greater activity in the NAC in response 
to high-calorie food items than do healthy-weight control subjects. ${ }^{58}$ In a cohort of 58 first-year female students, higher activation at baseline in the left NAC upon presentation of an image of palatable food was associated with increased weight gain after 6 months. ${ }^{17}$ Higher activity of the NAC in response to food images in obese individuals at the start of a weight loss program is predictive of less weight loss after 9 months. ${ }^{49}$ Thus, a higher activity in the NAC in response to food stimuli is a characteristic of the obese state and is predictive of weight gain.

\section{Obesity: An Addiction to Palatable Food?}

The preclinical evidence of addictive properties of food is numerous. A recent review summarizes the evidence from animal experimental research showing that the neurochemical and behavioral effects of intermittent and excessive sugar intake resemble those of other known substance addictions. ${ }^{3}$ Fat also induces behavioral and chemical alterations related to addiction, although the typical opioid-like withdrawal is not observed in rats, in contrast to sugar. ${ }^{4}$

Clinical data are also becoming increasingly available, most notably in the weight-loss surgery population. Patients in whom BS fails report an unchanged daily intake of food. ${ }^{12}$ After gastric bypass surgery $25 \%-39 \%$ of patients report "loss of control" eating behavior, which is associated with less weight loss. ${ }^{16,69}$ Approximately half of the people seeking medical attention for the treatment of their obesity meet the criteria for binge-eating disorder. This subpopulation loses less weight after BS. ${ }^{13}$ This supports the view that especially refractory cases of obesity could be attributed to some form of food addiction.

\section{DBS of the NAC and Addiction}

DBS of the NAC has positive effects on several forms of compulsive behavior. Experiments in rats show a reduction of addictive behavior related to alcohol ${ }^{31,35}$ and cocaine. ${ }^{64}$ Some clinical evidence indicates a favorable outcome of DBS with regard to compulsions in patients with obsessive-compulsive behavior. ${ }^{18}$ Furthermore, beneficial effects were reported in a case series with positive effects on alcoholism. ${ }^{65}$

\section{Current Evidence for DBS of the NAC in Obesity}

From a theoretical point of view the NAC makes a suitable target for DBS in the treatment of obesity, especially the forms related to food addiction. There are, however, only 5 animal experimental papers actually testing this concept. ${ }^{21,27,63,67,73}$ This leaves many questions still unsolved. In the study by Halpern et al. only two subjects received stimulation of the NAC core, which is insufficient to make a statement with regard to the effectiveness of stimulation in this region. ${ }^{27}$ Furthermore, only one frequency profile was used. It is known that the effects of stimulation may differ depending on the frequency used, and some effects on feeding behavior have been reported at stimulation at lower frequencies..$^{36,66}$ In the first experiment, stimulation was only performed over a 4-day course, and even over this period the effect seemed to diminish over time. ${ }^{27}$ This leaves the long-term effects of DBS ques- tionable, especially because relapse is a challenge in the treatment of obesity. ${ }^{12}$

Zhang et al. observed a strong effect on weight gain but did not monitor for side effects. ${ }^{73}$ Because the basal ganglia plays an important role in locomotion, it would be warranted to monitor for such side effects. Furthermore, it is well investigated that manipulations particularly in the caudal medial shell can induce fearful antipredator behavior. These occur generally between 0.48 and $1.4 \mathrm{~mm}$ ahead of bregma. ${ }^{51,53}$ Because the anterior location of the electrodes in these experiments was $1.2 \mathrm{~mm}$, the possibility of such an undesirable mechanism of weight loss cannot be ruled out. The third animal experimental paper by van der Plasse et al. assessed influence of NAC-DBS on intake in lean rats and found no significant effects. ${ }^{63}$ This finding is supported by the findings of Zhang's group: no effects of stimulation were observed in the lean rats. ${ }^{73}$ One of the hypotheses on the mechanism of action of DBS is a disruption of pathological oscillations to restore rhythmic activity and synchronization. ${ }^{33}$ In the absence of a pathological condition in lean rats, there are no pathological oscillations that can be modulated by DBS and these results can therefore not be extrapolated to the obese population. However, the decreased motivation to work for a sucrose reward does support the view that DBS of the NAC could modulate a dysfunctional reward mechanism in food addiction. $^{63}$

Results of the study by Doucette et al..$^{21}$ are consistent with the experiments by Halpern et al. ${ }^{27}$ Apart from the limitations that are thoroughly discussed in the paper (e.g., unequal group sizes at completion) the fact that the stimulation period was limited to the binge session needs to be addressed. Reduction of binge size might therefore be attributed to (motor) side effects and not to the actual alternation of the reward circuitry in the brain.

Wei et al. ${ }^{67}$ show that NAC shell (but not NAC core) stimulation inhibits palatable food consumption after food deprivation. The suggested underlying mechanism is that stimulation of the shell's GABAergic projections to the lateral hypothalamic area decreases the perceived reward value of that food and therefore may disturb the process of developing obesity.

Three case reports describe weight loss in obese patients following bilateral high-frequency stimulation of the NAC. However, two of the patients represent very specific subpopulations-obesity with a possible relationship to OCD and hypothalamic obesity- of the total obese population. ${ }^{30,45}$ The third patient suffered from depression. She underwent BS and DBS was performed before peak weight loss was to be expected (18 months after BS). A marked accelerated weight loss is reported after DBS. This may have been due to a dual effect of both treatments. ${ }^{62}$ Thus, these studies report on promising observations. However, because of their nature as single case reports, their value is limited.

\section{Conclusions}

With the increasing incidence of morbid obesity and the significant failure rates of current treatment modalities, new treatment strategies are warranted. The large interin- 
dividual variability in success rates for various interventions emphasizes the fact that causes for obesity are multifactorial. Animal experimental data and anecdotal case reports show promising results of DBS of the NAC in the treatment of obesity. The number of well-conducted animal studies, however, is very limited and the optimal anatomical target within the NAC and stimulation parameters have not been established. These matters need to be addressed before this strategy can be considered for clinical trials in humans. Multidisciplinary cooperation between clinicians (obesity specialists, endocrinologists, bariatric surgeons, psychiatrists, psychologists, neurophysiologists, and neurosurgeons) and preclinicians is warranted to address these issues and refine patient selection for clinical trials in DBS for obesity.

\section{References}

1. Adams TD, Davidson LE, Litwin SE, Kolotkin RL, LaMonte MJ, Pendleton RC, et al: Health benefits of gastric bypass surgery after 6 years. JAMA 308:1122-1131, 2012

2. Agüera Z, García-Ruiz-de-Gordejuela A, Vilarrasa N, Sanchez I, Baño M, Camacho L, et al: Psychological and personality predictors of weight loss and comorbid metabolic changes after bariatric surgery. Eur Eat Disord Rev 23:509-516, 2015

3. Avena NM, Rada P, Hoebel BG: Evidence for sugar addiction: behavioral and neurochemical effects of intermittent, excessive sugar intake. Neurosci Biobehav Rev 32:20-39, 2008

4. Avena NM, Rada P, Hoebel BG: Sugar and fat bingeing have notable differences in addictive-like behavior. J Nutr 139:623-628, 2009

5. Belanger SB, Wechsler FS, Nademin ME, Virden TB III: Predicting outcome of gastric bypass surgery utilizing personality scale elevations, psychosocial factors, and diagnostic group membership. Obes Surg 20:1361-1371, 2010

6. Berthoud HR, Lenard NR, Shin AC: Food reward, hyperphagia, and obesity. Am J Physiol Regul Integr Comp Physiol 300:R1266-R1277, 2011

7. Bétry C, Thobois S, Laville M, Disse E: Deep brain stimulation as a therapeutic option for obesity: a critical review. Obes Res Clin Pract [epub ahead of print], 2018

8. Bruce AS, Holsen LM, Chambers RJ, Martin LE, Brooks WM, Zarcone JR, et al: Obese children show hyperactivation to food pictures in brain networks linked to motivation, reward and cognitive control. Int J Obes 34:1494-1500, 2010

9. Buchwald H, Oien DM: Metabolic/bariatric surgery worldwide 2011. Obes Surg 23:427-436, 2013

10. Calle EE, Thun MJ, Petrelli JM, Rodriguez C, Heath CW Jr: Body-mass index and mortality in a prospective cohort of U.S. adults. N Engl J Med 341:1097-1105, 1999

11. Castellanos EH, Charboneau E, Dietrich MS, Park S, Bradley BP, Mogg K, et al: Obese adults have visual attention bias for food cue images: evidence for altered reward system function. Int J Obes 33:1063-1073, 2009

12. Christou NV, Look D, Maclean LD: Weight gain after shortand long-limb gastric bypass in patients followed for longer than 10 years. Ann Surg 244:734-740, 2006

13. Clark SM, Saules KK: Validation of the Yale Food Addiction Scale among a weight-loss surgery population. Eat Behav 14:216-219, 2013

14. David SP, Munafò MR, Johansen-Berg H, Smith SM, Rogers RD, Matthews PM, et al: Ventral striatum/nucleus accumbens activation to smoking-related pictorial cues in smokers and nonsmokers: a functional magnetic resonance imaging study. Biol Psychiatry 58:488-494, 2005
15. Day JJ, Wheeler RA, Roitman MF, Carelli RM: Nucleus accumbens neurons encode Pavlovian approach behaviors: evidence from an autoshaping paradigm. Eur J Neurosci 23:1341-1351, 2006

16. de Zwaan M, Hilbert A, Swan-Kremeier L, Simonich H, Lancaster K, Howell LM, et al: Comprehensive interview assessment of eating behavior 18-35 months after gastric bypass surgery for morbid obesity. Surg Obes Relat Dis 6:79-85, 2010

17. Demos KE, Heatherton TF, Kelley WM: Individual differences in nucleus accumbens activity to food and sexual images predict weight gain and sexual behavior. J Neurosci 32:5549-5552, 2012

18. Denys D, Mantione M, Figee M, van den Munckhof P, Koerselman F, Westenberg H, et al: Deep brain stimulation of the nucleus accumbens for treatment-refractory obsessivecompulsive disorder. Arch Gen Psychiatry 67:1061-1068, 2010

19. DiGiorgi M, Rosen DJ, Choi JJ, Milone L, Schrope B, Olivero-Rivera $\mathrm{L}$, et al: Re-emergence of diabetes after gastric bypass in patients with mid- to long-term follow-up. Surg Obes Relat Dis 6:249-253, 2010

20. Dixon JB: The effect of obesity on health outcomes. Mol Cell Endocrinol 316:104-108, 2010

21. Doucette WT, Khokhar JY, Green AI: Nucleus accumbens deep brain stimulation in a rat model of binge eating. Transl Psychiatry 5:e695, 2015

22. Fedoroff IC, Polivy J, Herman CP: The effect of pre-exposure to food cues on the eating behavior of restrained and unrestrained eaters. Appetite 28:33-47, 1997

23. Gearhardt AN, White MA, Potenza MN: Binge eating disorder and food addiction. Curr Drug Abuse Rev 4:201-207, 2011

24. Gearhardt AN, Yokum S, Orr PT, Stice E, Corbin WR, Brownell KD: Neural correlates of food addiction. Arch Gen Psychiatry 68:808-816, 2011

25. Greenberg BD, Gabriels LA, Malone DA Jr, Rezai AR, Friehs GM, Okun MS, et al: Deep brain stimulation of the ventral internal capsule/ventral striatum for obsessive-compulsive disorder: worldwide experience. Mol Psychiatry 15:64-79, 2010

26. Haber SN, Knutson B: The reward circuit: linking primate anatomy and human imaging. Neuropsychopharmacology 35:4-26, 2010

27. Halpern CH, Tekriwal A, Santollo J, Keating JG, Wolf JA, Daniels D, et al: Amelioration of binge eating by nucleus accumbens shell deep brain stimulation in mice involves D2 receptor modulation. J Neurosci 33:7122-7129, 2013

28. Halpern CH, Torres N, Hurtig HI, Wolf JA, Stephen J, Oh MY, et al: Expanding applications of deep brain stimulation: a potential therapeutic role in obesity and addiction management. Acta Neurochir (Wien) 153:2293-2306, 2011

29. Halpern CH, Wolf JA, Bale TL, Stunkard AJ, Danish SF, Grossman M, et al: Deep brain stimulation in the treatment of obesity. J Neurosurg 109:625-634, 2008

30. Harat MS: Nucleus accumbens stimulation in pathological obesity-case report. Stereotact Funct Neurosurg 91 (Suppl 1):255, 2013

31. Henderson MB, Green AI, Bradford PS, Chau DT, Roberts DW, Leiter JC: Deep brain stimulation of the nucleus accumbens reduces alcohol intake in alcohol-preferring rats. Neurosurg Focus 29(2):E12, 2010

32. Hollederer A: [Obesity in the population of North RhineWestphalia and its communities in the 2009 German Microcensus: prevalence, illness and prevention potential.] Dtsch Med Wochenschr 138:253-259, 2013 (Ger)

33. Karas PJ, Mikell CB, Christian E, Liker MA, Sheth SA: Deep brain stimulation: a mechanistic and clinical update. Neurosurg Focus 35(5):E1, 2013 
34. Kelley AE: Ventral striatal control of appetitive motivation: role in ingestive behavior and reward-related learning. Neurosci Biobehav Rev 27:765-776, 2004

35. Knapp CM, Tozier L, Pak A, Ciraulo DA, Kornetsky C: Deep brain stimulation of the nucleus accumbens reduces ethanol consumption in rats. Pharmacol Biochem Behav 92:474479, 2009

36. Krause M, German PW, Taha SA, Fields HL: A pause in nucleus accumbens neuron firing is required to initiate and maintain feeding. J Neurosci 30:4746-4756, 2010

37. Kuhn J, Gründler TO, Bauer R, Huff W, Fischer AG, Lenartz $\mathrm{D}$, et al: Successful deep brain stimulation of the nucleus accumbens in severe alcohol dependence is associated with changed performance monitoring. Addict Biol 16:620-623, 2011

38. Lawrence NS, Hinton EC, Parkinson JA, Lawrence AD: Nucleus accumbens response to food cues predicts subsequent snack consumption in women and increased body mass index in those with reduced self-control. Neuroimage 63:415-422, 2012

39. Lew EA, Garfinkel L: Variations in mortality by weight among 750,000 men and women. J Chronic Dis 32:563-576, 1979

40. Livhits M, Mercado C, Yermilov I, Parikh JA, Dutson E, Mehran A, et al: Preoperative predictors of weight loss following bariatric surgery: systematic review. Obes Surg 22:70-89, 2012

41. Maggard MA, Shugarman LR, Suttorp M, Maglione M, Sugerman HJ, Livingston EH, et al: Meta-analysis: surgical treatment of obesity. Ann Intern Med 142:547-559, 2005

42. Magro DO, Geloneze B, Delfini R, Pareja BC, Callejas F, Pareja JC: Long-term weight regain after gastric bypass: a 5-year prospective study. Obes Surg 18:648-651, 2008

43. Malik S, Mitchell JE, Engel S, Crosby R, Wonderlich S: Psychopathology in bariatric surgery candidates: a review of studies using structured diagnostic interviews. Compr Psychiatry 55:248-259, 2014

44. Mangas M, Moreira R: Deep brain stimulation for obsessive compulsive disorder: a literature review. J Obsessive Compuls Relat Disord 2:391-398, 2013

45. Mantione M, van de Brink W, Schuurman PR, Denys D: Smoking cessation and weight loss after chronic deep brain stimulation of the nucleus accumbens: therapeutic and research implications: case report. Neurosurgery 66:E218, 2010

46. Mathus-Vliegen EM: Long-term weight loss after bariatric surgery in patients visited at home outside the study environment. Obes Surg 16:1508-1519, 2006

47. Mehta S, Melhorn SJ, Smeraglio A, Tyagi V, Grabowski T, Schwartz MW, et al: Regional brain response to visual food cues is a marker of satiety that predicts food choice. Am J Clin Nutr 96:989-999, 2012

48. Meredith GE, Baldo BA, Andrezjewski ME, Kelley AE: The structural basis for mapping behavior onto the ventral striatum and its subdivisions. Brain Struct Funct 213:17-27, 2008

49. Murdaugh DL, Cox JE, Cook EW III, Weller RE: fMRI reactivity to high-calorie food pictures predicts short- and long-term outcome in a weight-loss program. Neuroimage 59:2709-2721, 2012

50. Neto LL, Oliveira E, Correia F, Ferreira AG: The human nucleus accumbens: where is it? A stereotactic, anatomical and magnetic resonance imaging study. Neuromodulation 11:13-22, 2008

51. Reynolds SM, Berridge KC: Fear and feeding in the nucleus accumbens shell: rostrocaudal segregation of GABA-elicited defensive behavior versus eating behavior. J Neurosci 21:3261-3270, 2001

52. Ribaric G, Buchwald JN, McGlennon TW: Diabetes and weight in comparative studies of bariatric surgery vs conventional medical therapy: a systematic review and meta-analysis. Obes Surg 24:437-455, 2014

53. Richard JM, Castro DC, Difeliceantonio AG, Robinson MJ, Berridge KC: Mapping brain circuits of reward and motivation: in the footsteps of Ann Kelley. Neurosci Biobehav Rev 37 (9 Pt A):1919-1931, 2013

54. Robinson TE, Berridge KC: The neural basis of drug craving: an incentive-sensitization theory of addiction. Brain Res Brain Res Rev 18:247-291, 1993

55. Salamone JD, Correa M: Dopamine and food addiction: lexicon badly needed. Biol Psychiatry 73:e15-e24, 2013

56. Schmidt U, Campbell IC: Treatment of eating disorders can not remain 'brainless': the case for brain-directed treatments. Eur Eat Disord Rev 21:425-427, 2013

57. Stice E, Yokum S, Bohon C, Marti N, Smolen A: Reward circuitry responsivity to food predicts future increases in body mass: moderating effects of DRD2 and DRD4. Neuroimage 50:1618-1625, 2010

58. Stoeckel LE, Weller RE, Cook EW III, Twieg DB, Knowlton RC, Cox JE: Widespread reward-system activation in obese women in response to pictures of high-calorie foods. Neuroimage 41: 636-647, 2008

59. Sturm R: The effects of obesity, smoking, and drinking on medical problems and costs. Health Aff (Millwood) 21:245253,2002

60. Sturm R: Increases in morbid obesity in the USA: 20002005. Public Health 121:492-496, 2007

61. Szalay C, Aradi M, Schwarcz A, Orsi G, Perlaki G, Németh L, et al: Gustatory perception alterations in obesity: an fMRI study. Brain Res 1473:131-140, 2012

62. Tronnier VM, Rasche D, Thorns V, Alvarez-Fischer D, Münte TF, Zurowski B: Massive weight loss following deep brain stimulation of the nucleus accumbens in a depressed woman. Neurocase 24:49-53, 2018

63. van der Plasse G, Schrama R, van Seters SP, Vanderschuren LJ, Westenberg HG: Deep brain stimulation reveals a dissociation of consummatory and motivated behaviour in the medial and lateral nucleus accumbens shell of the rat. PLoS One 7:e33455, 2012

64. Vassoler FM, Schmidt HD, Gerard ME, Famous KR, Ciraulo DA, Kornetsky C, et al: Deep brain stimulation of the nucleus accumbens shell attenuates cocaine priming-induced reinstatement of drug seeking in rats. J Neurosci 28:8735-8739, 2008

65. Voges J, Müller U, Bogerts B, Münte T, Heinze HJ: Deep brain stimulation surgery for alcohol addiction. World Neurosurg 80:28.e21-28.e31, 2013

66. Volkmann J, Herzog J, Kopper F, Deuschl G: Introduction to the programming of deep brain stimulators. Mov Disord 17 (Suppl 3):S181-S187, 2002

67. Wei N, Wang Y, Wang X, He Z, Zhang M, Zhang X, et al: The different effects of high-frequency stimulation of the nucleus accumbens shell and core on food consumption are possibly associated with different neural responses in the lateral hypothalamic area. Neuroscience 301:312-322, 2015

68. Weiner S, Sauerland S, Weiner RA, Pomhoff I: Quality of life after bariatric surgery-is there a difference? Chir Gastroenterol 21:34-36, 2005

69. White MA, Kalarchian MA, Masheb RM, Marcus MD, Grilo CM: Loss of control over eating predicts outcomes in bariatric surgery patients: a prospective, 24-month follow-up study. J Clin Psychiatry 71:175-184, 2010

70. Whitlock G, Lewington S, Sherliker P, Clarke R, Emberson J, Halsey J, et al: Body-mass index and cause-specific mortality in 900000 adults: collaborative analyses of 57 prospective studies. Lancet 373:1083-1096, 2009

71. Wilden JA, Qing KY, Hauser SR, McBride WJ, Irazoqui PP, Rodd ZA: Reduced ethanol consumption by alcohol-prefer- 
ring $(\mathrm{P})$ rats following pharmacological silencing and deep brain stimulation of the nucleus accumbens shell. J Neurosurg 120:997-1005, 2014

72. Yokum S, Ng J, Stice E: Attentional bias to food images associated with elevated weight and future weight gain: an fMRI study. Obesity (Silver Spring) 19:1775-1783, 2011

73. Zhang C, Wei NL, Wang Y, Wang X, Zhang JG, Zhang $\mathrm{K}$ : Deep brain stimulation of the nucleus accumbens shell induces anti-obesity effects in obese rats with alteration of dopamine neurotransmission. Neurosci Lett 589:1-6, 2015

\section{Disclosures}

The authors report no conflict of interest concerning the materials or methods used in this study or the findings specified in this paper.

\section{Author Contributions}

Conception and design: Oterdoom, G van Dijk. Acquisition of data: Oterdoom, G van Dijk, Verhagen. Analysis and interpretation of data: Oterdoom, G van Dijk. Drafting the article: Oterdoom, G van Dijk. Critically revising the article: all authors. Reviewed submitted version of manuscript: Oterdoom. Approved the final version of the manuscript on behalf of all authors: Oterdoom. Administrative/technical/material support: Oterdoom. Study supervision: JMC van Dijk.

\section{Correspondence}

D. L. Marinus Oterdoom: University Medical Center Groningen, The Netherlands. d.1.m.oterdoom@umcg.nl. 